\title{
Emergência de Plantas daninhas em lavouras de Feijão e de Trigo APós o Cultivo de Espécies de Cobertura de Solo ${ }^{1}$
}

\author{
Weed Emergence in Commom Bean and Wheat Crops after Cultivation of Coverage Plants
}

\author{
BRAZ, A.J.B.P. ${ }^{2}$, PROCÓPIO, S.O. ${ }^{2}$, CARGNELUTTI FILHO, A. ${ }^{3}$, SILVEIRA, P.M. ${ }^{4}$, \\ KLIEMANN, H.J. ${ }^{5}$, COBUCCI, T. ${ }^{4}$ e BRAZ, G.B.P. ${ }^{6}$
}

\begin{abstract}
RESUMO - O objetivo do trabalho foi avaliar a emergência das espécies de plantas daninhas Euphorbia heterophylla e Bidens pilosa em áreas de produção de feijão e de trigo, após o cultivo de plantas de cobertura. O trabalho foi conduzido em área sob sistema de plantio direto na palha, manejado por cinco anos consecutivos, na Fazenda Capivara, da Embrapa Arroz e Feijão, localizada no município de Santo Antônio de Goiás, GO. O solo do local é classificado como Latossolo Vermelho distrófico. Os tratamentos foram constituídos pela combinação de sete plantas de cobertura de solo: braquiarão (Brachiaria brizantha) - cv. Marandu; braquiarão em consórcio com o milho (Zea mays) - híbrido HT BRS 3150; guanduanão (Cajanus cajan); milheto (Pennisetum glaucum) - cv. BN-2; mombaça (Panicum maximum) - cv. Mombaça; sorgo granífero (Sorghum bicolor) - cv. BR 304; e estilosantes (Stylosanthes guianensis) - cv. Mineirão e por duas culturas cultivadas em sucessão nas áreas: feijão - cv. Pérola e trigo - Embrapa 42. Todas as plantas de cobertura foram cortadas no mesmo dia, utilizando-se um triturador de palhada, e deixadas na superfície do solo. As semeaduras do feijão e do trigo foram realizadas sessenta dias após o corte das culturas de cobertura. Foram realizadas duas contagens do número de plantas emergidas de E. heterophylla e de B. pilosa, separadas em três estágios de crescimento (plantas com menos de duas folhas, de duas a quatro folhas e com mais de quatro folhas). Entre as plantas de cobertura testadas, braquiarão e mombaça se mostraram as mais promissoras em reduzir a emergência de plantas daninhas em cultivos subseqüentes, apresentando resultados significativos na diminuição do número de plantas de E. heterophylla estabelecidas nas áreas cultivadas com feijão ou com trigo. Não se constataram diferenças quanto à capacidade das culturas de feijão e de trigo em reduzir a população de E. heterophylla e B. pilosa.
\end{abstract}

Palavras-chave: Phaseolus vulgaris, Triticum aestivum, Bidens pilosa, Euphorbia heterophylla.

\begin{abstract}
This study aimed to evaluate Euphorbia heterophylla and Bidens pilosa emergence in common bean- and wheat-producing areas, after cultivation of coverage plants. The experiment was carried out under a no-tillage system in straw, during five years, at Capivara Farm of Embrapa Arroz e Feijão, located in Santo Antônio de Goiás, GO. The local soil is classified as dystrophic Oxisol. The treatments combined seven coverage plants (Brachiaria brizantha - cv. Marandu; Brachiaria brizantha intercroping with corn (Zea mays) - hybrid HT BRS 3150; Cajanus cajan; Pennisetum glaucum - cv. BN-2; Panicum maximum - cv. Mombaça, Sorghum bicolor - cv. BR 304 and Stylosanthes guianensis - cv. Mineirão and two crops cultivated successively in the areas (common bean - cv. Pérola and wheat-Embrapa 42. All coverage plants were cut together by using a straw crusher and left on the ground; 60 days after being cut, the common bean and wheat plants were sowed. The number of plants obtained from Euphorbia heterophylla and Bidens pilosa was counted twice and the plants were separated into three growth stages (less than two leaves, from two to four leaves and more than
\end{abstract}

Recebido para publicação em 30.3.2006 e na forma revisada em 10.11.2006.

Professor da Faculdade de Agronomia da Universidade de Rio Verde - FESURV, 75901-970 Rio Verde-GO, <soprocopio@yahoo.com.br. ${ }^{3}$ Professor do Departamento de Ciências Exatas da Faculdade de Ciências Agrárias e Veterinárias, Universidade Estadual Paulista - FCAV/UNESP, 14884-900 Jaboticabal-SP. ${ }^{4}$ Pesquisador da Embrapa Arroz e Feijão, 75375-000 Santo Antônio de Goiás-GO. ${ }^{5}$ Professor da Escola de Agronomia da Universidade Federal de Goiânia - UFG, 74001-970 GoiâniaGO. ${ }^{6}$ Acadêmico do curso de Agronomia - FESURV. 
four leaves). Brachiaria brizantha and Panicum maximum coverages were efficient in reducing weed emergence, mainly $\boldsymbol{E}$. heterophylla in subsequent cultivation of common bean and wheat. No differences were observed in relation to common bean and wheat crop capacity of reducing $\boldsymbol{E}$. heterophylla and $\boldsymbol{B}$. pilosa population.

Keywords: Phaseolus vulgaris, Triticum aestivum, Bidens pilosa, Euphorbia heterophylla.

\section{INTRODUÇÃO}

A cobertura morta na superfície do solo é o principal componente do sucesso do Sistema Plantio Direto, atuando como reguladora de temperatura e da água do solo, no enriquecimento de matéria orgânica, na prevenção das diversas modalidades de erosão e no impedimento da emergência de plantas daninhas. A formação e a manutenção de cobertura morta nos trópicos, especialmente na região do Cerrado, no entanto, foram alguns dos principais obstáculos encontrados para o estabelecimento do sistema; altas temperaturas associadas à adequada umidade promovem a rápida decomposição dos resíduos vegetais incorporados ou não ao solo (Kluthcouski \& Stone, 2003).

Alvarenga et al. (2001) relataram que na escolha das plantas de cobertura é fato decisivo conhecer sua adaptação à região e habilidade em crescer em ambiente menos favorável, uma vez que as culturas comerciais são estabelecidas nas épocas mais propícias. Além disso, deve-se levar em consideração a produção de fitomassa, a disponibilidade de sementes, as condições do solo, a rusticidade quanto à tolerância ao déficit hídrico, a possibilidade de utilização comercial e o potencial dessas plantas de serem hospedeiras de pragas e doenças e, conforme Pettineli Neto et al. (2003), apresentarem alta capacidade de extrair nutrientes do solo e lenta decomposição.

De acordo com Sano et al. (1999), grande parte das áreas de Cerrados, cerca de 50 milhões de hectares, é ocupada com pastagens cultivadas, notadamente as gramíneas do gênero Brachiaria. Atualmente, observa-se a expansão da área cultivada com Brachiaria brizantha $\mathrm{cv}$. Marandu, de origem africana, perene, hábito de crescimento cespitoso, de ampla adaptação climática, boa tolerância ao sombreamento, grande produtora de massa verde e de bom valor nutritivo. Além do braquiarão, destacam-se outras espécies utilizadas como forrageiras e/ou como plantas de cobertura, como mombaça, milheto, sorgo, guandu e estilosantes.

A mombaça (Panicum maximum - cv. Mombaça) também é de origem africana, perene, crescimento cespitoso, com altura média de $1,65 \mathrm{~m}$, possui de 12 a $16 \%$ de proteína na matéria seca e é utilizada para pastoreio e silagem (Savidan et al., 1990). Apresenta algumas características, como alta exigência em nutrientes e estacionalidade de produção (Jank et al., 1994).

O milheto (Pennisetum glaucum) é uma planta anual, originária das savanas africanas. Apresenta crescimento cespitoso e ereto, sendo o ciclo de aproximadamente 130 dias (Salton \& Kichel, 1998). Contém de 7 a 12\% de proteína na massa seca e pode ser usado para pastoreio, feno, produção de grãos e silagem, sendo muito resistente à seca. Por essas razões, é uma boa opção para cultivo em safrinha na região dos Cerrados. Tem se expandido de forma acelerada devido a sua rusticidade, crescimento rápido, adaptação a solos de baixa fertilidade e excelente capacidade de produção de biomassa (Séguy et al., 1993; Pitol., 1999).

O sorgo (Sorghum bicolor) é originário da África e parte da Ásia e tem grande potencial em razão da sua resistência ao estresse hídrico, podendo ser usado em regiões de clima tropical e no semi-árido. Pode ser aproveitado como grão e forragem e, no SPD, fornece ótima palha para cobertura do solo (Teixeira Neto, 2002).

O guandu (Cajanus cajan) é uma leguminosa que tem seu centro de origem e diversidade genética na Índia (Godoy et al., 1997), sendo mais comum nas regiões tropicais e subtropicais. Apresenta porte arbustivo que pode atingir até quatro metros de altura. Segundo Alvarenga et al. (1995), possui habilidade de 
enraizamento em maiores profundidades, o que mostra seu maior potencial de absorção de água, bem como a possibilidade de reciclagem de nutrientes a partir das camadas mais profundas do solo.

O estilosantes (Stylosanthes guianensis cv. Mineirão) é uma leguminosa perene, semiereta, podendo atingir 2,5 $\mathrm{m}$ de altura. Apresenta boa adaptação aos solos ácidos e de baixa fertilidade, mas responde bem à adubação. Adapta-se bem às condições climáticas da região dos Cerrados, com verão quente e chuvoso e inverno frio e seco. Apresenta as seguintes características: grande produção de massa seca, alta retenção de folhas no período seco, grande resistência ao pastejo e ao pisoteio, capacidade de consorciação, resistência às pragas e doenças, boa aceitação pelos animais e nodulação com estirpes de Rhizobium (Embrapa, 1993).

No controle de plantas daninhas, a presença de uma camada de palha sobre a superfície do solo é de fundamental importância, devido ao efeito físico que limita a passagem de luz, criando dificuldades para que haja a germinação das sementes, e à barreira que forma, dificultando o crescimento inicial das plântulas; além disso, existem os efeitos alelopáticos oriundos da decomposição da fitomassa ou exsudação das raízes, que liberam substâncias que vão exercer efeito inibitório na germinação das sementes, ou interferindo em algum processo do seu desenvolvimento, de tal modo que o crescimento é retardado ou paralisado, havendo casos em que ocorre a morte da planta (Alvarenga et al., 2001). Além de proteger o solo contra a erosão, a manutenção da cobertura vegetal reduz a infestação de gramíneas anuais na cultura da soja (Vidal \& Bauman, 1996).

O objetivo do trabalho foi determinar as variações na emergência das espécies de plantas daninhas Euphorbia heterophylla e Bidens pilosa em áreas de produção de feijão e de trigo, após o cultivo de plantas de cobertura.

\section{MATERIAL E MÉTODOS}

O trabalho foi conduzido em área sob sistema de plantio direto na palha, manejado por cinco anos consecutivos, na Fazenda
Capivara, da Embrapa Arroz e Feijão, localizada no município de Santo Antônio de Goiás, GO (16 ${ }^{\circ} 27^{\prime}$ de latitude, 49 $17^{\circ}$ ' de longitude e $823 \mathrm{~m}$ de altitude).

O solo do local é classificado como Latossolo Vermelho distrófico, e a análise química (0 $20 \mathrm{~cm}$ de profundidade) antes da instalação do experimento apresentou os seguintes valores: $\mathrm{pH}\left(\mathrm{H}_{2} \mathrm{O}\right)=5,7 ; \mathrm{Ca}\left(\mathrm{mmol}_{\mathrm{c}} \mathrm{dm}^{-3}\right)=20,5$; $\mathrm{Mg}\left(\mathrm{mmol}_{\mathrm{c}} \mathrm{dm}^{-3}\right)=7,4 ; \mathrm{P}\left(\mathrm{mg} \mathrm{dm}^{-3}\right)=101$; $\mathrm{Cu}\left(\mathrm{mg} \mathrm{dm}{ }^{-3}\right)=2,2 ; \mathrm{Zn}\left(\mathrm{mg} \mathrm{dm}^{-3}\right)=8,1 ; \mathrm{Mn}$ $\left.\left.(\mathrm{mg} \mathrm{dm})^{-3}\right)=14 ; \mathrm{Fe}(\mathrm{mg} \mathrm{dm})^{-3}\right)=62 ;$ e matéria orgânica $\left(\mathrm{g} \mathrm{dm}^{-3}\right)=19$. A análise granulométrica apresentou os valores: areia $\left(\mathrm{g} \mathrm{kg}^{-1}\right)=490$, silte $\left(\mathrm{g} \mathrm{kg}^{-1}\right)=270$ e argila $\left(\mathrm{g} \mathrm{kg}^{-1}\right)=240$.

Os tratamentos foram constituídos pela combinação de sete plantas de cobertura de solo: braquiarão (Brachiaria brizantha cv. Marandu); braquiarão em consórcio com o milho (Zea mays - híbrido HT BRS 3150), guandu-anão (Cajanus cajan), milheto (Pennisetum glaucum - cv. BN-2), mombaça (Panicum maximum - cv. Mombaça), sorgo granífero (Sorghum bicolor - cv. BR 304) e estilosantes (Stylosanthes guianensis - cv. Mineirão) e por duas culturas cultivadas em sucessão nas áreas: feijão - cv. Pérola e trigo Embrapa 42.

O delineamento experimental foi o de blocos ao acaso, em parcelas subdivididas, com quatro repetições. As parcelas foram constituídas pelas plantas de cobertura e as subparcelas, pelas espécies cultivadas.

As parcelas mediram $6,0 \mathrm{~m}$ de largura por $20 \mathrm{~m}$ de comprimento. A adubação de plantio foi feita mecanicamente, utilizando-se $400 \mathrm{~kg} \mathrm{ha}^{-1}$ da fórmula comercial 5-30-15. A semeadura das plantas de cobertura foi realizada manualmente: guandu, milho e estilosantes no dia 5.12.2001; braquiarão e milheto, no dia 20.12.2001; mombaça, no dia 9.1.2002; e sorgo, no dia 23.1.2002. O consumo de sementes foi o seguinte: braquiarão $-20 \mathrm{~kg} \mathrm{ha}^{-1}$; milho - $20 \mathrm{~kg} \mathrm{ha}^{-1}$; guandu - $25 \mathrm{~kg} \mathrm{ha}^{-1}$; milheto - $40 \mathrm{~kg} \mathrm{ha} \mathrm{kg}^{-1}$; mombaça - $20 \mathrm{~kg} \mathrm{ha}^{-1}$; sorgo $10 \mathrm{~kg} \mathrm{ha}^{-1}$; e estilosantes $-1,4 \mathrm{~kg} \mathrm{ha}^{-1}$. Todas as plantas de cobertura foram cortadas no mesmo dia (17.4.2002), utilizando-se um triturador de palhada, e deixadas na superfície do solo. As subparcelas foram constituídas de oito linhas de 5 metros de comprimento, espaçadas 
de $0,45 \mathrm{~m}$, para a cultura do feijão, e de dez linhas de 5 metros de comprimento, espaçadas de $0,22 \mathrm{~m}$, para a cultura do trigo.

As semeaduras de feijão e trigo foram realizadas 60 dias após o corte das culturas de cobertura. Cinco dias antes do plantio do feijão e do trigo foi aplicado, na área experimental, o herbicida glyphosate na dose de $1,8 \mathrm{~kg} \mathrm{ha}^{-1}$ de equivalente ácido (e.a.). $\mathrm{Na}$ semeadura do feijão, a semeadora foi regulada para distribuir 17 sementes por metro, e na do trigo, 350 sementes viáveis por metro quadrado. A adubação de plantio para ambas as culturas foi de $400 \mathrm{~kg} \mathrm{ha}^{-1}$ da fórmula 4-20-20. Foi feita uma adubação de cobertura com $30 \mathrm{~kg} \mathrm{ha}^{-1}$ de N, aplicados em duas etapas: no feijoeiro aplicou-se a metade aos 15 dias após a emergência (DAE) e o restante aos 25 DAE; e, no trigo, um terço aos 15 DAE e o restante aos 30 DAE. A partir do segundo decênio de junho de 2002, foram realizadas irrigações em toda a área experimental. A quantidade aplicada de água e os demais dados meteorológicos do período encontram-se na Tabela 1.

Foram realizadas duas contagens do número de plantas emergidas de Euphorbia heterophylla e de Bidens pilosa, separadas em três estágios de crescimento (plantas com menos de duas folhas, de duas a quatro folhas e com mais de quatro folhas), sendo a primeira realizada aos 18 DAE das culturas e a segunda aos 30 DAE. As amostragens foram realizadas com a utilização de um quadrado metálico de 0,5 por $0,5 \mathrm{~m}$, sendo jogado ao acaso por duas vezes nas parcelas, perfazendo uma área total de $0,5 \mathrm{~m}^{2}$.

Após a tabulação dos dados, foi realizada a análise de variância. As médias das características significativas foram comparadas pelo teste de Duncan a 5\% de significância.

\section{RESULTADOS E DISCUSSÃO}

O cultivo prévio de braquiarão proporcionou os maiores níveis de massa seca na superfície do solo nas avaliações realizadas aos 18 e 30 DAE das culturas de feijão e trigo (Tabela 2). Aproximadamente 95 dias após o manejo (DAM) das plantas de braquiarão (data correspondente à avaliação de $30 \mathrm{DAE}$ das plantas de feijão e trigo), quase $8 \mathrm{t}$ de palhada ainda permaneciam sobre a superfície do solo, valor muito superior ao observado nas áreas cultivadas com as demais plantas de cobertura, onde se verificou que a quantidade de massa seca na superfície do solo aos 95 DAM variou

Tabela 1 - Temperaturas máximas, mínimas e médias (em $\left.{ }^{\circ} \mathrm{C}\right)$, precipitação pluvial e irrigação (em $\mathrm{mm}$ ), umidade relativa do ar (\%) por decênio, ocorridas no período de dezembro de 2001 a julho de 2002, registradas na Estação Meteorológica da Embrapa Arroz e Feijão, em Santo Antônio de Goiás-GO

\begin{tabular}{|c|c|c|c|c|c|}
\hline Mês & Fator & $\begin{array}{c}1^{\frac{0}{}} \\
\text { Decênio }\end{array}$ & $\begin{array}{c}2^{\underline{0}} \\
\text { Decênio }\end{array}$ & $\begin{array}{c}3^{0} \\
\text { Decênio }\end{array}$ & $\begin{array}{c}\text { Média/ } \\
\text { Total }\end{array}$ \\
\hline \multirow{5}{*}{ Dezembro } & T. Máxima & 24,5 & 30,1 & 27,6 & 27,4 \\
\hline & T. Mínima & 19,5 & 20,2 & 19,9 & 19,8 \\
\hline & T. Média & 23,1 & 23,8 & 20,3 & 22,4 \\
\hline & Prec. Pluvial & 38,6 & 32,1 & 91,3 & 162,0 \\
\hline & U. Relativa & 81,0 & 79,0 & 85,0 & 82,0 \\
\hline \multirow{5}{*}{ Janeiro } & T. Máxima & 29,8 & 27,8 & 31,4 & 29,6 \\
\hline & T. Mínima & 19,9 & 19,6 & 19,7 & 19,7 \\
\hline & T. Média & 23,4 & 22,7 & 23,5 & 23,2 \\
\hline & Prec. Pluvial & 32,2 & 141,4 & 42,5 & 216,1 \\
\hline & U. Relativa & 73,0 & 85,0 & 88,0 & 82,0 \\
\hline \multirow{5}{*}{ Fevereiro } & T. Máxima & 29,0 & 29,9 & 30,1 & 29,6 \\
\hline & T. Mínima & 17,7 & 17,0 & 18,1 & 17,6 \\
\hline & T. Média & 22,7 & 23,2 & 23,9 & 23,2 \\
\hline & Prec. Pluvial & 106,0 & 114,0 & 29,0 & 249,0 \\
\hline & U. Relativa & 90,0 & 94,0 & 90,0 & 91,0 \\
\hline \multirow{5}{*}{ Março } & T. Máxima & 31,9 & 31,2 & 29,4 & 30,8 \\
\hline & T. Mínima & 18,3 & 19,0 & 19,6 & 18,9 \\
\hline & T. Média & 23,9 & 23,7 & 23,3 & 23,6 \\
\hline & Prec. Pluvial & 12,5 & 53,3 & 110,1 & 175,9 \\
\hline & U. Relativa & 71,0 & 78,0 & 80,0 & 76,0 \\
\hline \multirow{5}{*}{ Abril } & T. Máxima & 31,6 & 30,8 & 31,1 & 31,1 \\
\hline & T. Mínima & 18,2 & 18,9 & 18,0 & 18,3 \\
\hline & T. Média & 24,2 & 24,1 & 24,1 & 24,1 \\
\hline & Prec. Pluvial & 22,5 & 12,2 & 0,0 & 34,7 \\
\hline & U. Relativa & 67,0 & 73,0 & 60,0 & 67,0 \\
\hline \multirow{6}{*}{ Maio } & T. Máxima & 31,7 & 31,3 & 28,1 & 30,3 \\
\hline & T. Mínima & 18,7 & $\begin{array}{l}17,5 \\
17,5\end{array}$ & 14,1 & 16,8 \\
\hline & T. Média & 24,2 & 23,9 & 20,7 & 22,9 \\
\hline & Prec. Pluvial & 1,5 & 0,0 & 12,7 & 14,2 \\
\hline & U. Relativa & 67,0 & 63,0 & 64,0 & 65,0 \\
\hline & Irrigação & 12,0 & 0,0 & 12,0 & 24,0 \\
\hline \multirow{6}{*}{ Junho } & T. Máxima & 30,1 & 30,1 & 28,9 & 29,7 \\
\hline & T. Mínima & 15,6 & 15,5 & 15,4 & 15,5 \\
\hline & T. Média & 22,3 & 22,3 & 21,5 & 22,0 \\
\hline & Prec. Pluvial & 0,0 & 0,0 & 0,0 & 0,0 \\
\hline & U. Relativa & 55,0 & 51,0 & 54,0 & 53,0 \\
\hline & Irrigação & 0,0 & 22,5 & 22,5 & 45,0 \\
\hline \multirow{6}{*}{ Julho } & T. Máxima & 28,2 & 30,8 & 31,3 & 30,1 \\
\hline & T. Mínima & 14,1 & 16,0 & 17,0 & 15,7 \\
\hline & T. Média & 20,7 & 23,1 & 23,7 & 22,5 \\
\hline & Prec. Pluvial & 0,0 & 0,0 & 0,0 & 0,0 \\
\hline & U. Relativa & 55,0 & 50,0 & 47,0 & 51,0 \\
\hline & Irrigação & 67,4 & 77,9 & 56,8 & 202,1 \\
\hline
\end{tabular}


Tabela 2 - Massa seca presente na superfície do solo da área experimental proveniente do cultivo prévio de sete espécies de plantas de cobertura, nos períodos de avaliação da emergência das plantas daninhas. Santo Antônio de Goiás-GO

\begin{tabular}{|l|c|c|}
\hline \multirow{2}{*}{ Planta de cobertura } & \multicolumn{2}{|c|}{$\begin{array}{c}\text { Massa seca na superfície do solo } \\
\left(\mathrm{kg} \mathrm{ha}^{-1}\right)\end{array}$} \\
\cline { 2 - 3 } & $\begin{array}{c}1^{\mathrm{a}} \text { avaliação } \\
\text { (18 DAE) }\end{array}$ & $\begin{array}{c}2^{\mathrm{a}} \text { avaliação } \\
\text { (30 DAE) }\end{array}$ \\
\hline Braquiarão + milho & 2.499 & 2.409 \\
\hline Braquiarão & 8.402 & 7.982 \\
\hline Estilosanantes & 1.680 & 1.520 \\
\hline Guandu & 3.033 & 2.827 \\
\hline Milheto & 3.531 & 3.315 \\
\hline Mombaça & 3.961 & 3.686 \\
\hline Sorgo & 2.508 & 2.218 \\
\hline
\end{tabular}

DAE: dias após a emergência das culturas de feijão e trigo.

de $1.520 \mathrm{~kg} \mathrm{ha}^{-1}$ no tratamento com estilosantes a $3.686 \mathrm{~kg} \mathrm{ha}^{-1}$ no tratamento com mombaça (Tabela 2). Constatou-se também que o consórcio entre braquiarão e milho produziu quantidade de massa seca muito inferior (aproximadamente três vezes menos) em relação ao cultivo isolado de braquiarão.

Foi observado efeito significativo das plantas de cobertura sobre a emergência de plantas de Euphorbia heterophylla (Tabela 3). O cultivo de feijão ou trigo não teve influência sobre a emergência dessa espécie de planta daninha (Tabela 4). Também não se verificou interação entre o cultivo prévio das plantas de cobertura e o cultivo dessas duas culturas sobre essa característica avaliada.

A emergência mais tardia de plantas de E. heterophylla (menos de duas folhas) nas áreas cultivadas com feijão ou com trigo, avaliada aos 18 DAE das culturas, foi menor nas parcelas que apresentavam sobre a superfície do solo palhada de braquiarão ou mombaça, apenas não diferindo do tratamento em que se cultivou sorgo (Tabela 3). Nessa mesma época de avaliação, observou-se que o cultivo anterior de braquiarão também se destacou em relação à contagem do número de plantas de $E$. heterophylla que se encontravam com duas a quatro folhas; entretanto, a utilização de mombaça como planta de cobertura não diferiu do efeito redutor proporcionado pelo braquiarão. Em relação à contagem das plantas de E. heterophylla que apresentavam mais de quatro folhas, sendo estas possivelmente as primeiras a emergirem na área, também realizada aos 18 DAE, braquiarão e estilosantes foram as coberturas que se destacaram; contudo, mombaça, sorgo, guandu e o consórcio entre braquiarão e milho equivaleram estatisticamente a esses dois tratamentos. Boller \& Gamero (2002) observaram, 60 dias após o manejo mecânico das espécies de cobertura aveia-preta, centeio e nabo forrageiro, diminuição no número de plantas daninhas de 91,33, 76,47 e 57,53\%, respectivamente, em relação ao pousio.

Tabela 3 - Média do número de plantas por $0,5 \mathrm{~m}^{2}$ de Euphorbia heterophylla emergidas em lavouras de feijão e trigo após o cultivo de diferentes espécies de cobertura em duas épocas de avaliação, média geral e coeficiente de variação. Santo Antônio de Goiás-GO

\begin{tabular}{|l|c|c|c|c|c|c|}
\hline \multirow{2}{*}{ Planta de cobertura } & \multicolumn{3}{|c|}{18 DAE } & \multicolumn{3}{c|}{30 DAE } \\
\cline { 2 - 7 } & $<2$ folhas & $2 \mathrm{a} 4$ folhas & $>4$ folhas & $<2$ folhas & $2 \mathrm{a} 4$ folhas & $>4$ folhas \\
\hline Braquiarão + milho & $6,81 \mathrm{~b}$ & $7,88 \mathrm{a}$ & $0,94 \mathrm{ab}$ & $4,50 \mathrm{ab}$ & $4,25 \mathrm{a}$ & $3,75 \mathrm{ab}$ \\
\hline Braquiarão & $1,19 \mathrm{~d}$ & $1,56 \mathrm{c}$ & $0,50 \mathrm{~b}$ & $1,75 \mathrm{~b}$ & $0,25 \mathrm{~b}$ & $1,75 \mathrm{~b}$ \\
\hline Estilosantes & $6,50 \mathrm{~b}$ & $8,50 \mathrm{a}$ & $0,31 \mathrm{~b}$ & $5,75 \mathrm{ab}$ & $5,75 \mathrm{a}$ & $5,25 \mathrm{ab}$ \\
\hline Guandu & $12,25 \mathrm{a}$ & $10,00 \mathrm{a}$ & $1,19 \mathrm{ab}$ & $9,75 \mathrm{a}$ & $6,50 \mathrm{a}$ & $6,75 \mathrm{ab}$ \\
\hline Milheto & $5,75 \mathrm{bc}$ & $8,00 \mathrm{a}$ & $2,06 \mathrm{a}$ & $5,50 \mathrm{ab}$ & $4,25 \mathrm{a}$ & $8,25 \mathrm{a}$ \\
\hline Mombaça & $1,44 \mathrm{~d}$ & $3,69 \mathrm{bc}$ & $0,81 \mathrm{ab}$ & $3,50 \mathrm{~b}$ & $2,50 \mathrm{ab}$ & $2,00 \mathrm{~b}$ \\
\hline Sorgo & $3,06 \mathrm{~cd}$ & $4,75 \mathrm{~b}$ & $0,94 \mathrm{ab}$ & $4,25 \mathrm{~b}$ & $2,75 \mathrm{ab}$ & $6,75 \mathrm{ab}$ \\
\hline Média geral & 5,29 & 6,34 & 0,96 & 5,00 & 3,75 & 4,93 \\
\hline CV $(\%)$ & 31,20 & 23,19 & 39,06 & 45,01 & 48,59 & 50,38 \\
\hline
\end{tabular}

Médias de tratamentos não seguidas de mesma letra diferem a 5\% de probabilidade pelo teste de Duncan. DAE = dias após a emergência das culturas de feijão e trigo. 
Tabela 4 - Média do número de plantas por $0,5 \mathrm{~m}^{2}$ de Euphorbia heterophylla emergidas durante o ciclo de desenvolvimento das culturas de feijão e trigo, média geral e coeficiente de variação. Santo Antônio de Goiás-GO

\begin{tabular}{|l|c|c|c|c|c|c|}
\hline \multirow{2}{*}{ Cultura } & \multicolumn{3}{|c|}{18 DAE } & \multicolumn{3}{c|}{30 DAE } \\
\cline { 2 - 7 } & $<2$ folhas & 2 a 4 folhas & $>4$ folhas & $<2$ folhas & 2 a 4 folhas & $>$ folhas \\
\hline Feijão & 5,14 & 5,93 & 1,14 & 4,57 & 3,71 & 4,79 \\
\hline Trigo & 5,43 & 6,75 & 0,79 & 5,43 & 3,79 & 5,07 \\
\hline Média geral & 5,29 & 6,34 & 0,96 & 5,00 & 3,75 & 4,93 \\
\hline CV $(\%)$ & 31,20 & 23,19 & 39,06 & 45,01 & 48,59 & 50,38 \\
\hline
\end{tabular}

Médias de tratamentos não diferem pelo teste $\mathrm{F}$ a $5 \%$ de probabilidade. DAE = dias após a emergência das culturas de feijão e trigo.

Menor número de plantas de E. heterophylla com menos de duas folhas aos 30 DAE foi contabilizado nos tratamentos com braquiarão, mombaça e sorgo, sendo significativamente menor a quantidade de plantas emergidas sob a palhada de guandu (Tabela 3). Quando se realizou o cultivo de braquiarão anteriormente ao das culturas de feijão e trigo, constatou-se que aos 30 DAE foi encontrada nessas áreas, em média, menos de uma planta de E. heterophylla com duas a quatro folhas por metro quadrado, enquanto nas áreas cultivadas com estilosantes e guandu observaram-se, em média, mais de 10 plantas por metro quadrado. Esses resultados não corroboram os encontrados por Maciel et al. (2003), os quais verificaram que a presença da palhada de Brachiaria decumbens (6 t ha-1) na superfície do solo não influenciou o índice de velocidade de germinação de sementes de E. heterophylla.

$\mathrm{Na}$ avaliação de plantas de E. heterophylla que apresentavam crescimento mais avançado (acima de quatro folhas), foi observado menor número nas áreas onde se cultivou braquiarão e mombaça, sendo constatada nas áreas onde se semeou milheto a maior quantidade de plantas de $E$. heterophylla que se encontravam nesse estágio de crescimento. Esses dados indicam uma correlação inversa entre quantidade de palhada sobre o solo (proporcionada pelo cultivo de braquiarão) e redução da emergência de E. heterophylla. Solos sem ou com pouca cobertura vegetal tendem a apresentar maior amplitude térmica do que solos protegidos (Salton \& Mielnickzuk, 1995), podendo favorecer a quebra da dormência das sementes de plantas daninhas. Outra possível explicação para a menor densidade de E. heterophylla em áreas com maiores níveis de palhada seria a redução da quantidade e modificação da qualidade da luz que atinge as sementes desta espécie nos solos com palha na superfície (Theisen et al., 2005).

Na Tabela 4 estão apresentadas as médias do número de plantas emergidas em $0,5 \mathrm{~m}^{2}$ de $E$. heterophylla nas parcelas cultivadas com feijão e trigo, mostrando que não houve superioridade entre essas espécies na redução da emergência dessa planta daninha, em todos os estágios de crescimento avaliados, independentemente do cultivo anterior das espécies de cobertura.

Como anteriormente observado em E. heterophylla, somente houve efeito significativo das plantas de cobertura sobre a emergência de plantas de Bidens pilosa. O cultivo de feijão ou trigo novamente não diferiu quanto à emergência dessa espécie invasora, não ocorrendo também interação entre os dois fatores avaliados.

Na avaliação da emergência de plantas de $B$. pilosa realizada aos $18 \mathrm{DAE}$, observou-se que o cultivo prévio de mombaça diminuiu o número de plantas de $B$. pilosa que apresentavam duas a quatro folhas em relação ao cultivo com estilosantes, independentemente da cultura que foi implantada em seqüência (Tabela 5), não diferindo, todavia, dos cultivos dos tratamentos consórcio entre braquiarão e milho, braquiarão, guandu, milheto e sorgo. Nessa mesma avaliação não se detectaram diferenças entre todos os tratamentos de cobertura, em relação à população emergida de $B$. pilosa que se encontrava com menos de duas ou com mais de quatro folhas.

Aos 30 DAE, também não foram verificadas diferenças quanto à capacidade de cada cobertura de impedir ou diminuir a emergência 
mais tardia de plantas de B. pilosa (com menos de duas folhas). Contudo, na contagem das plantas dessa invasora que se encontravam em estágio de crescimento mais avançado (duas a quatro folhas e acima de quatro folhas), constatou-se que o cultivo de estilosantes foi o menos eficiente em reduzir a emergência e/ou o estabelecimento de B. pilosa (Tabela 5), não diferindo, no entanto, dos tratamentos com milheto e sorgo na contagem das plantas com mais de quatro folhas. Esses dados não indicam a mesma correlação vista na avaliação de E. heterophylla, pois o cultivo da espécie de cobertura que proporcionou maior massa vegetal sobre o solo (braquiarão) não se destacou na redução da emergência de $B$. pilosa. Entretanto, verificou-se alta correlação entre a maior emergência dessa planta daninha e a menor produção e manutenção da palhada, constatada no tratamento em que se utilizou estilosantes como planta de cobertura.
Como constatado, em relação a E. heterophylla, não se observaram diferenças entre o cultivo do feijão e o do trigo quanto à capacidade de reduzir a emergência e o estabelecimento de plantas de B. pilosa (Tabela 6).

Entre as plantas de cobertura testadas, braquiarão (Brachiaria brizantha) e mombaça (Panicum maximum cv. Mombaça) se mostraram as mais promissoras em reduzir de forma significativa a emergência de plantas daninhas em cultivos subseqüentes.

De forma geral, os resultados mostram que a utilização de técnicas voltadas à alta produção de palhada que apresente menores taxas de decomposição é um método eficiente no manejo de plantas daninhas em cultivos agrícolas, devendo sempre estar inserido dentro do Manejo Integrado de Plantas Daninhas, o que possibilitará menor dependência do controle químico, auxiliando na maior sustentabilidade dos agroecossistemas.

Tabela 5 - Média do número de plantas por $0,5 \mathrm{~m}^{2}$ de Bidens pilosa emergidas em lavouras de feijão e trigo após o cultivo de diferentes espécies de cobertura em duas épocas de avaliação, média geral e coeficiente de variação. Santo Antônio de Goiás-GO

\begin{tabular}{|l|c|c|c|c|c|c|}
\hline \multirow{2}{*}{ Planta de cobertura } & \multicolumn{3}{|c|}{18 DAE } & \multicolumn{3}{c|}{$30 \mathrm{DAE}$} \\
\cline { 2 - 7 } & $<2$ folhas & $2 \mathrm{a} 4$ folhas & $>4$ folhas & $<2$ folhas & $2 \mathrm{a} 4$ folhas & $>4$ folhas \\
\hline Braquiarão + milho & $0,56 \mathrm{a}$ & $1,19 \mathrm{ab}$ & $0,06 \mathrm{a}$ & $1,00 \mathrm{a}$ & $0,75 \mathrm{~b}$ & $0,25 \mathrm{~b}$ \\
\hline Braquiarão & $0,06 \mathrm{a}$ & $0,44 \mathrm{ab}$ & $0,00 \mathrm{a}$ & $1,00 \mathrm{a}$ & $1,75 \mathrm{~b}$ & $0,75 \mathrm{~b}$ \\
\hline Estilosantes & $1,31 \mathrm{a}$ & $2,44 \mathrm{a}$ & $0,00 \mathrm{a}$ & $0,50 \mathrm{a}$ & $5,25 \mathrm{a}$ & $3,00 \mathrm{a}$ \\
\hline Guandu & $0,38 \mathrm{a}$ & $1,63 \mathrm{ab}$ & $0,00 \mathrm{a}$ & $0,25 \mathrm{a}$ & $1,75 \mathrm{~b}$ & $0,50 \mathrm{~b}$ \\
\hline Milheto & $1,50 \mathrm{a}$ & $1,31 \mathrm{ab}$ & $0,00 \mathrm{a}$ & $1,00 \mathrm{a}$ & $1,88 \mathrm{~b}$ & $1,88 \mathrm{ab}$ \\
\hline Mombaça & $0,38 \mathrm{a}$ & $0,31 \mathrm{~b}$ & $0,00 \mathrm{a}$ & $1,00 \mathrm{a}$ & $0,25 \mathrm{~b}$ & $0,50 \mathrm{~b}$ \\
\hline Sorgo & $0,44 \mathrm{a}$ & $1,50 \mathrm{ab}$ & $0,25 \mathrm{a}$ & $0,25 \mathrm{a}$ & $0,25 \mathrm{~b}$ & $1,25 \mathrm{ab}$ \\
\hline Média geral & 0,66 & 1,26 & 0,04 & 0,71 & 1,70 & 1,16 \\
\hline CV $(\%)$ & 47,43 & 45,39 & 16,52 & 51,69 & 58,18 & 55,10 \\
\hline
\end{tabular}

Médias de tratamentos não seguidas de mesma letra diferem a 5\% de probabilidade pelo teste de Duncan. DAE = dias após a emergência das culturas de feijão e trigo.

Tabela 6 - Média do número de plantas por $0,5 \mathrm{~m}^{2}$ de Bidens pilosa emergidas durante o ciclo de desenvolvimento das culturas de feijão e trigo, média geral e coeficiente de variação. Santo Antônio de Goiás-GO

\begin{tabular}{|l|c|c|c|c|c|c|}
\hline \multirow{2}{*}{ Cultura } & \multicolumn{3}{|c|}{18 DAE } & \multicolumn{3}{c|}{30 DAE } \\
\cline { 2 - 7 } & $<2$ folhas & 2 a 4 folhas & $>4$ folhas & $<2$ folhas & 2 a 4 folhas & $>4$ folhas \\
\hline Feijão & 0,46 & 1,16 & 0,02 & 0,79 & 1,86 & 1,71 \\
\hline Trigo & 0,86 & 1,36 & 0,07 & 0,64 & 1,54 & 0,61 \\
\hline Média geral & 0,66 & 1,26 & 0,04 & 0,71 & 1,70 & 1,16 \\
\hline CV $(\%)$ & 47,43 & 45,39 & 16,52 & 51,69 & 58,18 & 55,10 \\
\hline
\end{tabular}

Média de tratamentos não diferem pelo teste $\mathrm{F}$ a $5 \%$ de probabilidade. DAE = dias após a emergência das culturas de feijão e trigo. 


\section{LITERATURA CITADA}

ALVARENGA, R. C. et al. Plantas de cobertura de solo para sistema plantio direto. Inf. Agropec., v. 22, p. 25-36, 2001.

ALVARENGA, R. G. et al. Características de alguns adubos verdes de interesse para a conservação e recuperação de solos. Pesq. Agropec. Bras., v. 30, p. 175-185, 1995.

BOLLER, W.; GAMERO, C. A. Acúmulo de matéria seca e supressão de plantas daninhas por culturas para cobertura do solo. R. Plantio Direto, n. 69, p. 29-31, 2002.

EMPRESA BRASILEIRA DE PESQUISA AGROPECUÁRIA - EMBRAPA. Centro de Pesquisa Agropecuária dos Cerrados. Recomendações para estabelecimento e utilização do Stylosantes guianensis cv. Mineirão. Planaltina: EmbrapaCPAC; Campo Grande: Embrapa-CNPGC, 1993. 7 p. (Embrapa-CPAC. Comunicado Técnico, 67; EmbrapaCNPGC. Comunicado Técnico, 49).

GODOY, R. et al. Avaliação agronômica e seleção de germoplasma de guandu forrageiro (Cajanus cajan L. Mill) proveniente da Índia. R. Bras. Zootec., v. 26, p. 447-453, 1997.

JANK, L. et al. Avaliação do germoplasma de Panicum maximum introduzido da África. 1. Produção forrageira. R. Bras. Zootec., v. 23, p. 433-440, 1994.

KLUTHCOUSKI, J.; STONE, L. F. Palhada de braquiária no sistema plantio direto. In: KLUTHCOUSKI, J.; AIDAR, H.; STONE, L. F. (Ed.). Integração lavoura pecuária: agregação de valores, custo e sustentabilidade. Santo Antônio de Goiás: Embrapa Arroz e Feijão, 2003. p. 499-522.

MACIEL, C. D. G. et al. Influência do manejo da palhada de capim-braquiária (Brachiaria decumbens) sobre o desenvolvimento inicial de soja (Glycine max) e amendoimbravo (Euphorbia heterophylla). Planta Daninha, v. 21, p. 365-373, 2003.

PETTINELli NETO, A.; MATEUS, G. P.; CRUSCIOL, C. A. C. Modificações dos atributos químicos do solo e produção de aveia preta em função da cobertura do solo. In: CONGRESSO BRASILEIRO DE CIÊNCIA DO SOLO, 29. 2003, Ribeirão Preto. Anais... Ribeirão Preto: Sociedade Brasileira de Ciência do Solo, 2003. CD-ROM.
PITOL, C. O milheto em sistemas de plantio direto. In: WORKSHOP INTERNACIONAL DE MILHETO, 1999, Planaltina. Anais... Planaltina: Embrapa Cerrados, 1999. p. 69-71.

SALTON, J. C.; MIELNICKZUK, J. Relações entre sistemas de preparo, temperatura e umidade de um podzólico vermelho escuro de Eldorado do Sul (RS). R. Bras. Ci. Solo, v. 19, p. 313-319, 1995.

SALTON, J. C.; KICHEL, A. N. Milheto, uma alternativa para cobertura do solo e alimentação animal. R. Plantio Direto, n. 45, p. 41-43, 1998.

SANO, E. E.; BARCELLOS, A. O.; BEZERRA, H. S. Área e distribuição espacial de pastagens cultivadas no cerrado brasileiro. Planaltina: Embrapa Cerrados, 1999. 21 p. (Embrapa Cerrados. Boletim de Pesquisa, 3).

SAVIDAN, Y. H.; JANK, L.; COSTA, J. C. G. Registro de 25 acessos selecionados de Panicum maximum. Campo Grande: Embrapa-CNPGC, 1990. 68 p. (Embrapa-CNPGC. Documentos, 44).

SEGUY, L. et al. Gestão dos solos e das culturas nas áreas de fronteiras agrícolas dos Cerrados úmidos do Centro Oeste Brasileiro, ano agrícola 1992-1993. Lucas do Rio Verde: RPA/CIRAD, 1993. 91 p.

TEIXEIRA NETO, M. L. Efeito de espécies vegetais para cobertura, no sistema plantio direto na região dos cerrados, sobre as propriedades do solo. 2002. $151 \mathrm{f}$. Dissertação (Mestrado em Produção Vegetal) - Universidade Federal de Goiás, Goiânia, 2002.

THEISEN, G.; VIDAL, R. A.; FLECK, G. N. Redução da infestação de Brachiaria plantaginea em soja pela cobertura do solo com palha de aveia-preta. Pesq. Agropec. Bras., v. 35, p. 753-756, 2005.

VIDAL, R. A.; BAUMAN, T. T. Surface wheat (Triticum aestivum) residues, giant foxtail (Setaria faberi), and soybean (Glycine max) yield. Weed Sci., v. 44, p. 939-943, 1996. 